\title{
Phosphorylation of ER $\alpha$ at serine 118 in primary breast cancer and in tamoxifen- resistant tumours is indicative of a complex role for ER $\alpha$ phosphorylation in breast cancer progression
}

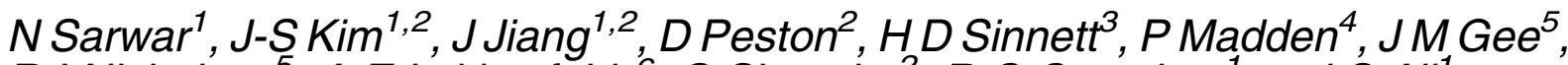 \\ $R$ I Nicholson ${ }^{5}, A$ E Lykkesfeldt ${ }^{6}$, S Shousha ${ }^{2}, R C$ Coombes $^{1}$ and S Ali ${ }^{1}$ \\ Departments of ${ }^{1}$ Oncology, ${ }^{2}$ Histopathology, ${ }^{3}$ Surgery and ${ }^{4}$ Social Science and Medicine, Imperial College London, Hammersmith \\ Hospital Campus, Du Cane Road, London W12 ONN, UK \\ ${ }^{5}$ Tenovus Centre for Cancer Research, Welsh School of Pharmacy, Cardiff University, Cardiff, UK \\ ${ }^{6}$ Department of Tumor Endocrinology, Institute of Cancer Biology, Danish Cancer Society, DK-2100, Copenhagen Ø, Denmark \\ (Requests for offprints should be addressed to S Ali; Email: simak.ali@imperial.ac.uk)
}

\begin{abstract}
Oestrogen receptor- $\alpha(E R \alpha)$ is an important prognostic marker in breast cancer and endocrine therapies are designed to inhibit or prevent ER $\alpha$ activity. In vitro studies have indicated that phosphorylation of $E R \alpha$, in particular on serine 118 (S118), can result in activation in a ligandindependent manner, thereby potentially contributing to resistance to endocrine agents, such as tamoxifen and aromatase inhibitors. Here we report the immunohistochemistry (IHC) of S118 phosphorylation in 301 primary breast tumour biopsies. Surprisingly, this analysis shows that S118 phosphorylation is higher in more differentiated tumours, suggesting that phosphorylation at this site is associated with a good prognosis in patients not previously treated with endocrine agents. However, we also report that $\mathrm{S} 118$ phosphorylation was elevated in tumour biopsies taken from patients who had relapsed following tamoxifen treatment, when compared to pre-treatment biopsies. Taken together, these data are consistent with the view that $\mathbf{S} 118$ phosphorylation is a feature of normal $E R \alpha$ function and that increases in levels of phosphorylation at this site may play a key role in the emergence of endocrine resistance in breast cancer.
\end{abstract}

Endocrine-Related Cancer (2006) 13 851-861

\section{Introduction}

It is now clear that oestrogens play a central role in promoting breast cancer development and progression (Ali \& Coombes 2002). In this respect, oestrogen action is mediated through the oestrogen receptors ER $\alpha$ and ER $\beta$. Two-thirds of all primary breast cancers are known to express ER $\alpha$, where its presence correlates with a better prognosis and likelihood of response to endocrine therapies. These findings have led to effective strategies aimed at preventing ER activation by reducing oestrogen levels using inhibitors of the oestrogen biosynthetic enzyme, aromatase (Johnston \& Dowsett 2003) or, in the case of pre-menopausal women, using luteinizing hormonereleasing hormone (LHRH) agonists that act to inhibit oestrogen synthesis by suppression of ovarian function (Klijn et al. 2001).

In a second and highly effective approach in breast cancer treatment, tamoxifen is used as a selective oestrogen receptor modulator (SERM) that binds to $\mathrm{ER}$, resulting in a conformational change, leading to inhibition of receptor activity. Thus, tamoxifen acts by competing with oestrogen for binding to ER, leading to inhibition of tumour growth. For many patients, tamoxifen is still the first line adjuvant agent in the treatment of ER $\alpha$-positive breast cancer and provides 
response in pre-menopausal women, as well as in postmenopausal patients. Further, tamoxifen is an effective treatment for about half of all patients with ER $\alpha$ positive metastatic disease and prolongs disease-free survival and overall survival in the adjuvant setting (EBCTC Group 1998, Osborne 1998, Ali \& Coombes 2002). Additionally, tamoxifen treatment is protective for the incidence of contralateral invasive breast cancer, which has led to the proposal that it may be efficacious for breast cancer prevention. This hypothesis has been confirmed by the results of several clinical trials with tamoxifen and another SERM, raloxifene, which show reduction in early incidence of breast cancer in women in high-risk groups (Powles 2002, Cuzick et al. 2003).

A major complication in breast cancer treatment is the recognition that a substantial proportion of patients with ER $\alpha$-positive breast cancer are de novo resistant to tamoxifen and many others who initially respond eventually acquire resistance (Ali \& Coombes 2002, Ring \& Dowsett 2004). Similar data have been obtained for other anti-oestrogens (Howell et al. 2004) and for aromatase inhibitors, although thirdgeneration aromatase inhibitors may show delayed emergence of endocrine resistance, when compared with tamoxifen (Johnston \& Dowsett 2003). The mechanisms underlying this resistance are still poorly understood and identification of the factors and pathways responsible for the development of resistance is therefore an important diagnostic and therapeutic challenge in breast cancer research.

It was originally proposed that resistance to endocrine agents involved the loss of ER $\alpha$. However, it is now clear that the majority of tamoxifen-resistant tumours continue to express ER $\alpha$ (Robertson 1996, Ring \& Dowsett 2004). Furthermore, tumours resistant to one form of endocrine therapy frequently respond to alternative endocrine treatment. For example, the aromatase inhibitor anastrozole has been shown to give response in around $30 \%$ of patients who had developed resistance to tamoxifen (Buzdar \& Howell 2001). Similar responses have been achieved following relapse on tamoxifen, with the potent anti-oestrogen ICI 182780, also known as Fulvestrant (Howell et al. 1996). These findings provide in vivo evidence to indicate that $\mathrm{ER} \alpha$ continues to play an important role in cancer cell growth in resistant tumours.

$\mathrm{ER} \alpha$ is a member of the nuclear receptor superfamily of ligand-activated transcription factors, which is activated upon binding oestrogen (Chawla et al. 2001). Oestrogen binding regulates ER $\alpha$ dimerization, intracellular localization and stability. Additionally, oestrogen binding stimulates $\mathrm{ER} \alpha$ phosphorylation at several sites. The best studied of these is serine 118 (S118) (Ali et al. 1993, Le Goff et al. 1994). The oestrogen-stimulated phosphorylation of S118 is mediated by the TFIIH kinase cdk7 and phosphorylation by cdk7 stimulates ER $\alpha$ activity (Joel et al. 1998, Chen et al. 2000, Chen et al. 2002, Ito et al. 2004). Furthermore, S118 phosphorylation can be induced by growth factors such as epidermal growth factor (EGF) and insulin-like growth factor (IGF), likely acting through direct phosphorylation of S118 by extracellular signal regulated kinase (ERK) $1 / 2$ mitogen-activated protein kinase (MAPK) (Kato et al. 1995). The growth factor and MAPK-induced phosphorylation of S118 can result in ligand-independent activation of ER $\alpha$ (Bunone et al. 1996), which could be important in endocrine resistance, particularly given that MAPK activity is significantly increased in a large proportion of breast cancers (Sivaraman et al. 1997) and elevated MAPK levels correlate with a poor response to endocrine therapies (Gee et al. 2001).

These findings suggest that ligand-independent activation of ER $\alpha$ through phosphorylation of S118 may contribute to de novo and/or acquired resistance to endocrine therapies. In order to address this possibility we undertook a study to establish protocols for the immunohistochemical detection of ER $\alpha$ phosphorylated at S118 (P-S118) and to determine whether there is any relationship between levels of P-S118 and prognostic factors, survival and outcome of endocrine therapies.

\section{Materials and methods}

\section{Human breast cancer samples}

A total of 301 breast cancer cases were selected from the Charing Cross Hospital Breast Tumour Bank. All had been obtained from surgery carried out between 1981 and 2003. The patient's age at presentation, tumour grade, tumour size, ER $\alpha$ and progesterone receptor (PR) status were recorded, as were the dates of first relapse and of death. The majority of the tumours (94\%) were ER $\alpha$-positive at the time of initial surgery, as defined by ligand-binding assay or immunohistochemical staining. ER $\alpha$ and PR status were re-determined at the time of this study by immunohistochemical staining as described below. The clinico-pathological characteristics of the patient cohort are shown in Table 1. Response to endocrine therapy was determined by examining the clinical records of patients who had assessable disease and had received either neoadjuvant hormonal therapy or palliative hormonal treatments for metastatic disease. An additional 21 patients were identified and their 
Table 1 Relationship between levels of ER $\alpha$ phosphorylated at serine 118 and clinical features

\begin{tabular}{|c|c|c|c|c|}
\hline & $\begin{array}{c}\text { P-S118- } \\
\text { negative } \\
n(\%)^{b}\end{array}$ & $\begin{array}{c}\text { P-S118- } \\
\text { positive } \\
n(\%)^{a}\end{array}$ & $\begin{array}{c}\text { Chi- } \\
\text { squared }^{c}\end{array}$ & $P$ value $^{\mathrm{d}}$ \\
\hline \multicolumn{5}{|l|}{ Age (years) } \\
\hline$<50$ & $23(30)$ & $15(70)$ & & \\
\hline $50-70$ & $34(18)$ & $55(82)$ & 5.12 & 0.08 \\
\hline$>70$ & $6(16)$ & $13(84)$ & & \\
\hline \multicolumn{5}{|l|}{ Grade } \\
\hline I & $4(11)$ & $32(90)$ & & \\
\hline II & 27 (15) & 149 (85) & 22.35 & $<0.001$ \\
\hline III & $31(40)$ & $46(60)$ & & \\
\hline Unknown & 1 & 11 & & \\
\hline \multicolumn{5}{|l|}{ Tumour size } \\
\hline$<2 \mathrm{~cm}$ & $23(21)$ & 87 (79) & & \\
\hline $2-5 \mathrm{~cm}$ & 29 (20) & $113(80)$ & 2.70 & 0.26 \\
\hline$>5 \mathrm{~cm}$ & $9(35)$ & 17 (65) & & \\
\hline Unknown & 2 & 21 & & \\
\hline \multicolumn{5}{|l|}{ Nodal status } \\
\hline Negative & $19(21)$ & 73 (79) & 0.20 & 0.66 \\
\hline Positive & $39(27)$ & $108(73)$ & & \\
\hline Unknown & 5 & 57 & & \\
\hline \multicolumn{5}{|l|}{$\mathrm{ER} \alpha$} \\
\hline Negative & $15(79)$ & $4(21)$ & 41.20 & $<0.001$ \\
\hline Positive & 48 (17) & 234 (83) & & \\
\hline \multicolumn{5}{|l|}{ PR } \\
\hline Negative & $26(27)$ & 71 (73) & 2.91 & 0.09 \\
\hline Positive & 37 (18) & $166(82)$ & & \\
\hline$N D^{e}$ & 0 & 1 & & \\
\hline \multicolumn{5}{|l|}{ c-erbB2 } \\
\hline Negative & $17(21)$ & $66(79)$ & 1.02 & 0.31 \\
\hline Positive & $7(30)$ & $16(70)$ & & \\
\hline ND & 39 & 156 & & \\
\hline \multicolumn{5}{|l|}{ P-MAPK } \\
\hline Negative & $41(44)$ & $53(56)$ & 41.00 & $<0.001$ \\
\hline Positive & $22(11)$ & $180(89)$ & & \\
\hline ND & 0 & 5 & & \\
\hline
\end{tabular}

aP-S118-positive, H-score,,++++++ .

${ }^{b}$ Percentage of cases in each horizontal group that were P-S118-negative.

'Pearson's chi-squared test. The analysis was carried out using known samples only.

${ }^{d}$ A value of $P<0.05$ denotes a statistically significant difference. ${ }^{\mathrm{e}} \mathrm{ND}$ denotes not determined.

evaluation of response to treatment was determined using response evaluation criteria in solid tumours (RECIST) (Therasse et al. 2000). Time to progression was defined as the time from initial diagnosis to documented date of first relapse, and the time to death was defined as the time from initial diagnosis to death.

Clinical records of patients who had become resistant to hormonal therapy were also examined, and where a repeat biopsy had been obtained at relapse, whilst the patient was taking tamoxifen, or for patients who relapsed 1-5 years following the completion of tamoxifen treatment. Immunostaining for $\mathrm{ER} \alpha$ and P-S118 was performed in breast cancer samples obtained before and after becoming resistant to hormonal therapy. The mean time to relapse in this group of patients was 51 months $(n=21$; range $17-112$ months following initial diagnosis). The study fulfilled the Institutional Ethics Review Board's guidelines for the use of stored tissues samples.

\section{Immunohistochemistry}

Sections of $4 \mu \mathrm{m}$ were cut from formalin-fixed, paraffin-embedded archival tissue blocks and mounted on 3-aminopropyltriethoxysilane (APES; Sigma) treated slides and dried overnight at $37{ }^{\circ} \mathrm{C}$. Sections were placed in a $60{ }^{\circ} \mathrm{C}$ oven for $1 \mathrm{~h}$ prior to being dewaxed in xylene and rehydrated through graded alcohols. Endogenous peroxidase was blocked by immersing in $2 \%$ hydrogen peroxide in methanol for $10 \mathrm{~min}$. Antigen retrieval was carried out by pressure cooking, using $10 \mathrm{mM}$ citrate buffer $\mathrm{pH} 6.0$ and immunohistochemistry (IHC) was performed as previously described (Taylor et al. 1998), using mouse monoclonal antibodies for P-S118 (cat. no. 2511; New England Biolabs, UK), activated mitogen-activated protein kinase (MAPK, cat. no. 4376; New England Biolabs, Herts, UK), ER $\alpha$ (cat. no. VP-E613; Vector Laboratories, Peterborough, UK), progesterone receptor (PR, cat. no. MU328-UC; Biogenex, USA) and a rabbit polyclonal antibody for c-erbB2 (cat. no. A 0485; Dako). P-S118 levels were scored by a trained histopathologist, using the modified McCarty's $\mathrm{H}$-scoring system, which was based on the percentage of positive cells and the intensity of staining to provide a total score varying from 0 to 300 . The staining was designated as negative $(\mathrm{H}$-score $<50)$, weakly positive (+; H-score of 51-100), moderately positive $(++$; 101-200) or strongly positive $(+++, 201-300)$ (McCarty et al. 1985). For determining the specificity of immunostaining for P-S118, the antibody was preincubated with a 100-fold molar excess of a peptide having the sequence 112-HPPPQLSPFLQPH-124 or the same peptide in which the serine residue was substituted by phosphoserine.

\section{Statistical analyses}

All statistical analyses were carried out using Stata 7 software (http://www.stata.com/). P-S118 scores were compared with different clinico-pathological features using the Pearson chi-squared test ( $\chi$ tests) for categorical variables and the $t$ and Mann-Whitney tests for continuous data. Association between S118 status and a number of clinico-pathological 
features were investigated using chi-squared tests (where applicable Fisher's exact tests were used). The Wilcoxon matched pairs signed rank test was used to determine whether there was a significant difference in the distribution of S118 phosphorylation before and after treatment failure. Survival was compared in each of the clinico-pathological features using log rank tests for equality of survivor function.

\section{Cell culture}

All cells were cultured at $37{ }^{\circ} \mathrm{C}$ in a humidified $5 \% \mathrm{v} / \mathrm{v}$ $\mathrm{CO}_{2}$ incubator. MCF7 cells (ATCC, USA) were maintained in Dulbecco's Modified Eagle's Medium (DMEM) containing 10\% fetal calf serum (FCS). For preparation of whole cell lysates MCF7 cells plated on 9-cm dishes were transferred to DMEM lacking phenol red and containing 5\% dextran-coated charcoalstripped fetal calf serum (DSS) for $72 \mathrm{~h}$, prior to the addition of oestradiol-17 $\beta \quad\left(\mathrm{E}_{2} ; 10 \mathrm{nM}\right)$, 4-hydroxytamoxifen (OHT; $100 \mathrm{nM}$ ), ICI 182780 (ICI; $100 \mathrm{nM}$ ), epidermal growth factor (EGF; $100 \mathrm{ng} / \mathrm{ml}$ ) or phorbol myristate acetate (PMA; $100 \mathrm{ng} / \mathrm{ml}$ ) for $15 \mathrm{~min}$, as appropriate. The MAPK/ERK-kinase (MEK) inhibitor, $\mathrm{U} 0126(25 \mu \mathrm{M})$ was added $1 \mathrm{~h}$ prior to the addition of $\mathrm{E}_{2}$, EGF or PMA. An equal volume of the solvent in which the different reagents were prepared was added to the appropriate samples to control for solvent effects. MCF7 Tam-R and matched MCF7 cells were maintained in RPMI 1640 lacking phenol red, supplemented with 5\% DSS and containing OHT (100 nM), as described (Knowlden et al. 2003). MCF7/TAMR-4 have previously been described (Madsen et al. 1997). MCF7/ TAMR-4 and matched MCF7 parental cells were maintained in DMEM/F12 lacking phenol red, supplemented with $1 \%$ FCS and containing $10^{-6} \mathrm{M}$ tamoxifen, as described (Lykkesfeldt et al. 1994, Madsen et al. 1997), but may also be maintained with the addition of $100 \mathrm{nM}$ of the more potent OHT, as used in this study. For preparing lysates from the Tam-R, MCF7/TAMR-4 and their respective matched parental MCF7 cells, the media were replaced by medium lacking FCS and in the absence of tamoxifen for $24 \mathrm{~h}$ prior to harvesting.

\section{Cell lysate preparation and immunoblotting}

Lysates were prepared essentially as previously described (Joel et al. 1998), by washing the cells with pre-warmed $\left(37^{\circ} \mathrm{C}\right) \mathrm{PBS}$. Then $0.5 \mathrm{ml}$ of $2 \times$ sample buffer $(0.12 \mathrm{M}$ Tris-HCl, $\mathrm{pH}$ 6.8, 4\% SDS, $20 \%$ glycerol, $0.2 \mathrm{M}$ dithiothreitol, $0.008 \%$ bromophenol blue), heated to $100{ }^{\circ} \mathrm{C}$, was added to each 9 -cm dish. The cells were scraped into $1.5 \mathrm{ml}$ Eppendorf tubes in a heat block at $100{ }^{\circ} \mathrm{C}$. The extracts were heated for
$10 \mathrm{~min}$, cooled on ice, aliquots obtained and then stored at $-80{ }^{\circ} \mathrm{C}$ prior to use. Cell lysates were resolved using $10 \%$ SDS-PAGE and immunoblotting was carried out as previously described (Chen et al. 2002) using monoclonal antibodies for ER $\alpha$ (NCL-L-ER-6F11; Novocastra Laboratories, UK), P-S118 (cat. no. 2511; New England Biolabs, UK), ERK1, C-16 (Santa Cruz Biotechnology, Santa Cruz, CA, USA), phosphorylated ERK1/2 MAPK (cat. no. 9106; New England Biolabs) and $\beta$-actin (C-2; Santa Cruz).

\section{Results}

\section{ER $\propto$ phosphorylation in MCF7 breast cancer cells}

We have previously used antibodies specific to ER $\alpha$ phosphorylated at S118 and transient transfection of COS- 1 cells to demonstrate that $\mathrm{ER} \alpha$ is phosphorylated by ERK1/2 MAPK in a ligand-independent manner, but that the $E_{2}$-stimulated phosphorylation of S118 is not mediated by MAPK. Rather, the $\mathrm{E}_{2}$-stimulated phosphorylation of S118 was shown to be mediated by the TFIIH protein kinase, Cdk7 (Chen et al. 2000, 2002). In order to confirm that two distinct signalling pathways in breast cancer cells also mediate S118 phosphorylation, total lysates were prepared from MCF7 cells treated with $\mathrm{E}_{2}, \mathrm{PMA}$ or EGF. In the case of $\mathrm{E}_{2}, \mathrm{P}-\mathrm{S} 118$ levels were raised within $5 \mathrm{~min}$, peaked at $30 \mathrm{~min}$ and started to fall after 45 min (data not shown). With PMA or EGF, P-S118 levels rose within $5 \mathrm{~min}$, peaked at $15 \mathrm{~min}$ and started to fall thereafter (data not shown). Figure 1A shows the levels of P-S118 at $15 \mathrm{~min}$ following the addition of $\mathrm{E}_{2}$, EGF or PMA. As expected, pretreatment with the MEK inhibitor, U0126, prevented S118 phosphorylation upon addition of EGF or PMA (Fig. 1B), but did not have any inhibitory effect on the stimulation of S118 phosphorylation by $\mathrm{E}_{2}$ (Fig. 1C). Interestingly, the anti-oestrogens OHT and ICI 182780 also stimulated S118 phosphorylation (Fig. 1C). U0126 also failed to inhibit S118 phosphorylation stimulated by OHT and ICI.

The steady-state levels of P-S118 were next investigated in several MCF7 sub-lines derived by long-term culturing in the presence of tamoxifen in the culture medium (Lykkesfeldt et al. 1994, Knowlden et al. 2003). In the tamoxifen-resistant MCF7 sub-lines investigated the steady-state levels of P-S118 were elevated in the absence of $E_{2}$, OHT or serum, when compared with the parental MCF7 cells, as were levels of activated (phosphorylated) MAPK (Fig. 2). These data suggest that increased MAPK activity, as well as ER $\alpha$ phosphorylation and consequently increased ER $\alpha$ activity may feature in tamoxifen resistance in breast cancer. 


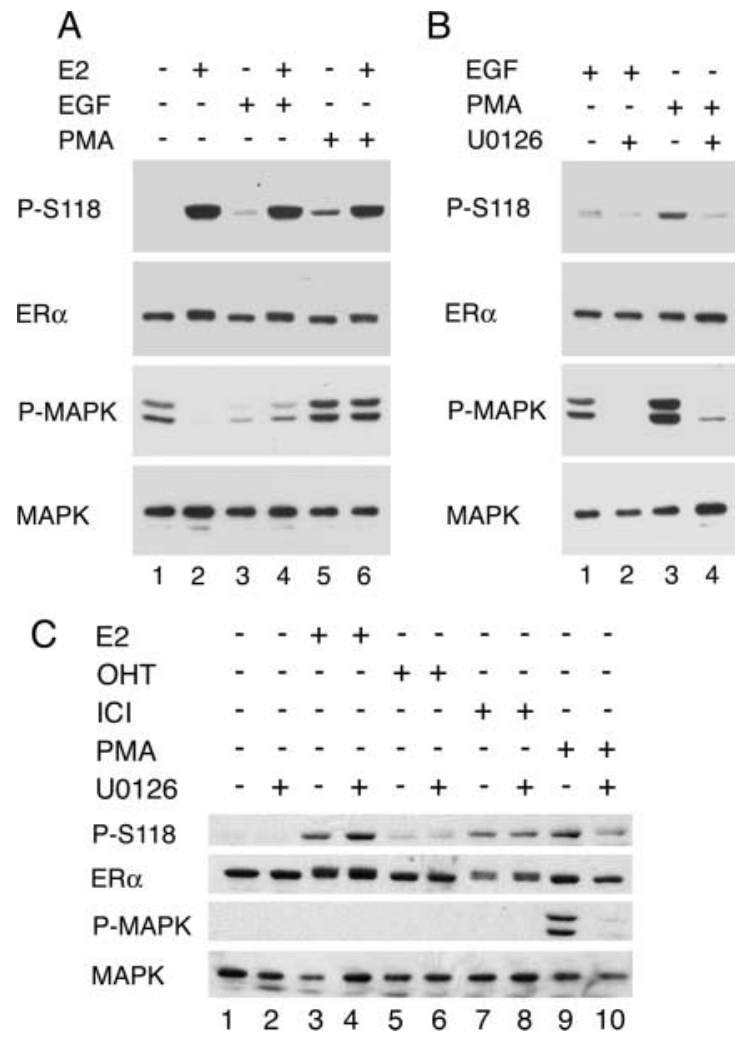

Figure 1 Immunoblotting of MCF7 human breast cancer cells for $\mathrm{ER} \alpha$ phosphorylation at serine 118. MCF7 cells were harvested 15 min following the addition of $E_{2}, O H T, I C I$, EGF or PMA, as indicated. U0126 was added $1 \mathrm{~h}$ prior to the addition of ligands or growth factors. An equal volume of the solvent used to prepare the different ligands was added to the no-ligand controls. MCF7 lysates were resolved by $10 \%$ SDS-PAGE and immunoblotting was carried out using antibodies for P-S118, $\mathrm{ER} \alpha, \mathrm{P}-\mathrm{MAPK}$ and MAPK, as shown.

\section{Immunohistochemical detection of ER $\alpha$ phosphorylated at serine 118 in human breast tumours}

The utility of the P-S118 antibody for IHC was explored by developing protocols using formalin-fixed, paraffinembedded MCF7 tumours generated in nude mice (data not shown) and subsequently optimized using primary breast tumour blocks from several ER $\alpha$-positive and ER $\alpha$-negative tumours. In establishing the IHC methodology, there was no detectable immunostaining of $\mathrm{ER} \alpha$-negative cases with the P-S118 antibody (data not shown), whereas nuclear staining was detectable in many of the ER $\alpha$-positive cases (Fig. 3A, B). The specificity of staining was determined by pre-incubating the P-S118 antibody with a 100-fold excess of peptides encoding amino acids 112-124 of human ER $\alpha$, in which a serine or a phosphoserine was present at position 118. Pre-incubation of the P-S118 antibody

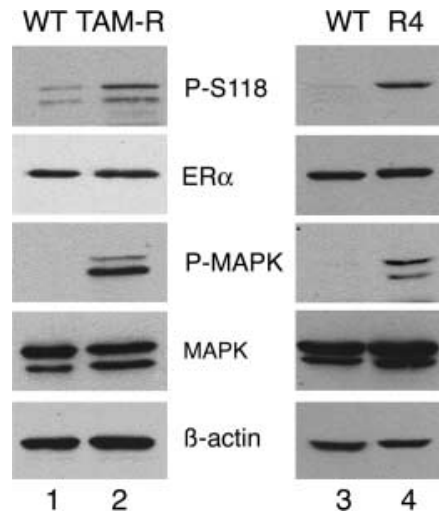

Figure 2 Immunoblotting of tamoxifen-resistant MCF7-derived sub-lines for P-S118. The tamoxifen-resistant sub-lines, together with parental MCF7 cells from which the lines were derived, were cultured in medium lacking FCS for $24 \mathrm{~h}$ prior to harvesting. The lysates were resolved by $10 \%$ SDS-PAGE and immunoblotting was carried out using antibodies for P-S118, $\mathrm{ER} \alpha, \mathrm{P}$-MAPK, MAPK and $\beta$-actin, as shown. TAM-R and matched unselected (wild-type) MCF7 lines have been described (Knowlden et al. 2003) (lanes 1, 2). TAM-R4 and the matched unselected (wild-type) MCF7 have also been described (Madsen et al. 1997) (lanes 3, 4).

with the phosphorylated peptide resulted in loss of immunostaining (Fig. 3C), whereas the unphosphorylated peptide did not affect immunostaining (Fig. 3D). Further, competition was also performed using a peptide corresponding to amino acids $97-112$ of human $E R \alpha$ and containing a phosphoserine at position 106 that is followed by a proline (as is S118), a previously described ER $\alpha$ phosphorylation site (Le Goff et al. 1994). Pre-incubation of the P-S118 antibody with this peptide, did not inhibit P-S118 staining (data not shown). Collectively, these data indicate that the P-S118 antibody specifically recognizes ER $\alpha$ phosphorylated at S118.

Tissue blocks from our cohort of 301 patients were sectioned for IHC to detect P-S118. In total, 282 (94\%) of the tumours were ER $\alpha$-positive, as determined by IHC. Of the 282 ER $\alpha$-positive patients, 234 (83\%) had detectable nuclear staining for P-S118.

\section{Relationship between P-S118 staining and known prognostic features of breast tumours}

Analysis of P-S118 positive cases by comparing the number of positive specimens in any given year showed that there was no statistical relationship between P-S118 staining and archival age, indicating that it is possible to evaluate relationships between P-S118 staining and prognostic features in this patient group. However, statistical analyses showed that there was no relationship between P-S118 staining (two 


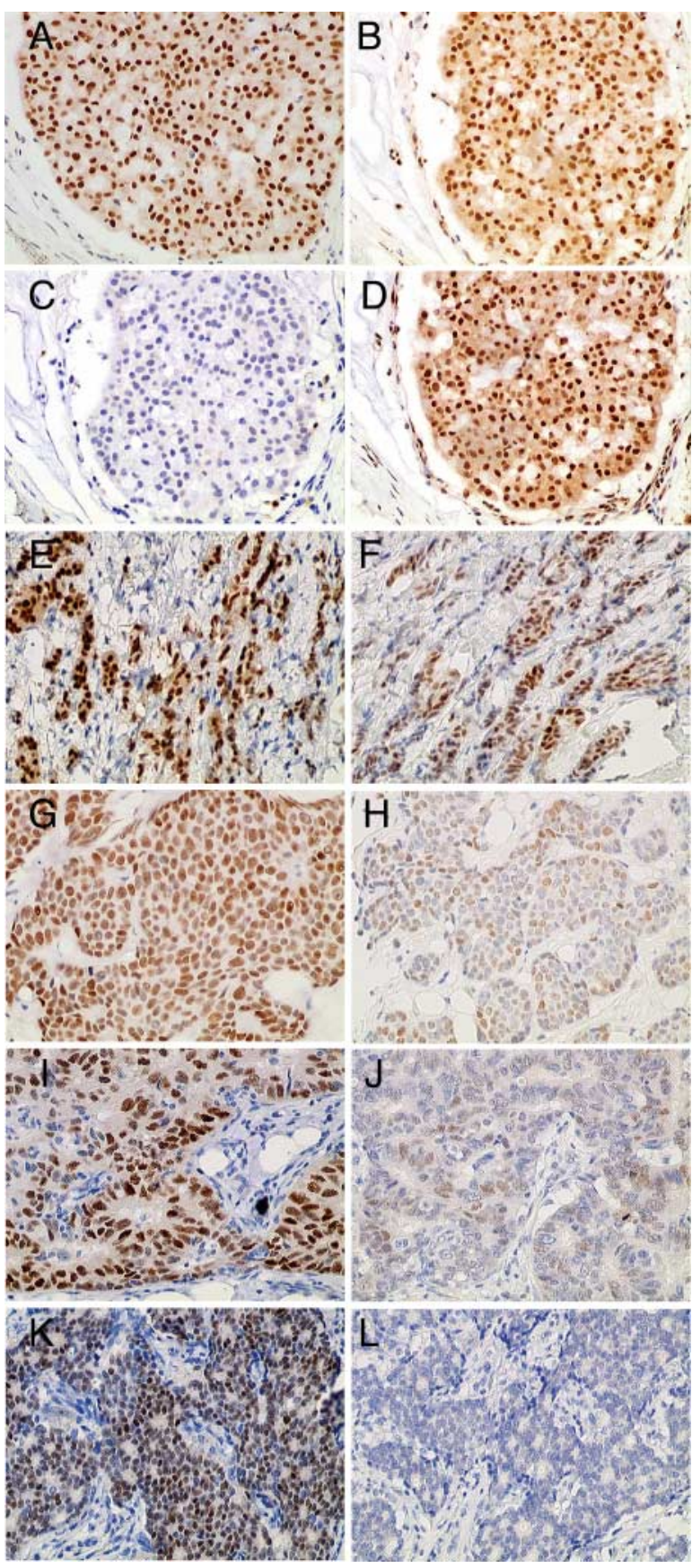

Figure $3 \mathrm{Immunohistochemical} \mathrm{detection} \mathrm{of} \mathrm{ER} \alpha$ phosphorylated at S118 in human breast cancer sections (magnification $\times 200$ ). Serial sections from a breast cancer biopsy were immunostained using antibodies for $\mathrm{ER} \alpha(\mathrm{A})$ or P-S118 (B-D), in the presence or absence of a peptide-containing phosphoserine (C) or serine (D) at position 118. Serial sections from four breast tumours that were strongly $\mathrm{ER} \alpha$-positive $(\mathrm{H}$-score: $+++)(E, G, I, K)$ are shown alongside staining of a serial section for P-S118, scored as $+++(F),++(H),+(J)$ and $-(\mathrm{L})$, respectively. levels negative and positive) and tumour size, nodal status, PR and c-erbB2 status (Table 1). By contrast, there was a positive correlation of P-S118 with ER $\alpha$ $(P<0.001)$. Furthermore, there was a clear inverse relationship between P-S118 staining and tumour grade $(P<0.001)$, with lower grade tumours associated with higher $\mathrm{H}$-scores for P-S118 staining $(P<0.001)$. There was also some evidence of an association between P-S118 and age $(P=0.08)$. However, P-S118 was not associated with survival, i.e. there was no statistically significant difference in survival between those positive and negative for P-S118 (log rank test for equality of survivor function $\chi^{2}, 1$ degree of freedom $=1.43, P=0.23$ ). Similarly there was no evidence of a statistically significant difference in survival for ER $\alpha$ ( $\log$ rank test for equality of survivor function $\chi^{2}, 1$ degree of freedom $=2.07, P=0.15$ ), and c-erbB2 (log rank test for equality of survivor function $\chi^{2}, 1$ degree of freedom $=1.59, P=0.21$ ) in this cohort of patients. With respect to the other factors, there was a statistically significant difference in survival with regard to nodal status (log rank test for equality of survivor function $\chi^{2}, 1$ degree of freedom $=14.82$, $P<0.001$ ), grade (log rank test for equality of survivor function $\chi^{2}, 2$ degrees of freedom $\left.=13.46, P=0.001\right)$, tumour size (log rank test for equality of survivor function $\chi^{2}, 2$ degrees of freedom $=16.22, P<0.001$ ), age (log rank test for equality of survivor function $\chi^{2}$, 2 degrees of freedom $=7.45, P=0.02)$ and PR $(\log$ rank test for equality of survivor function $\chi^{2}, 1$ degree of freedom $=5.41, P=0.02$ ).

IHC was also carried out using antibodies specific for activated MAPK. In total, 202 (68\%) of the 296 cases immunostained scored positive for nuclear, phosphorylated (activated) MAPK. There was a positive correlation between phospho-MAPK staining and P-S118 staining $(P<0.001)$, as might have been expected, given that ERK1/2 MAPK phosphorylates $\mathrm{ER} \alpha$ at S118. There was no evidence of a correlation between P-MAPK and survival (log rank test for equality of survivor function $\chi^{2}, 1$ degree of freedom $=0.46, P=0.50$ ).

\section{P-S118 levels do not predict for response to endocrine treatments following relapse on tamoxifen}

As described above, immunostaining of 301 primary breast cancer biopsies showed a positive correlation of P-S118 staining with $\mathrm{ER} \alpha$, as well as a negative correlation with tumour grade, and evidence for an association with PR status $(P=0.09)$. These data suggest that phosphorylation of $\mathrm{S} 118$ is a marker of better 
prognosis and likelihood of response to endocrine treatment. We identified a group of patients who presented with ER $\alpha$-positive primary breast cancer, were given adjuvant tamoxifen following surgical resection of the primary tumour and who then relapsed, at which point they received second-line endocrine agents. The patients in this group were subsequently scored as responders and non-responders according to RECIST criteria (Therasse et al. 2000). IHC of the primary breast cancer biopsies from these patients for P-S118 revealed that levels of P-S118 immunostaining were variable in both groups and there was no correlation between P-S118 staining and response.

\section{Comparison of $\mathbf{S} 118$ phosphorylation in breast cancer pre- and post-tamoxifen treatment}

The above data indicate that P-S118 levels in primary breast tumours are not predictive of response to endocrine therapies. However, for patients who initially respond and then relapse, it is possible that $\mathrm{P}-\mathrm{S} 118$ levels increase during acquisition of resistance. Indeed, in MCF7-derived models of tamoxifen resistance P-S118 levels are elevated, as are levels of activated MAPK (Fig. 2). IHC was performed on biopsies from 21 patients who relapsed, either whilst receiving tamoxifen or after they had completed 5 years on tamoxifen, and for whom biopsy material taken prior to the initiation of tamoxifen treatment, was also available. Comparison of $\mathrm{H}$-scores showed that P-S118 levels were increased following tumour regrowth (Table 2). Overall, there was a statistically significant difference in the distribution of S118 phosphorylation before and after treatment $(z=-2.357, P=0.02)$. There were 2 comparisons in which S118 phosphorylation was higher pre-treatment, 11 where phosphorylation was higher post-treatment

Table 2 Levels of serine 118 phosphorylation in primary tumours and biopsies taken following relapse after tamoxifen adjuvant therapy ${ }^{\mathrm{a}}$

\begin{tabular}{lccc}
\hline & P-S118 & ER $\boldsymbol{\alpha}$ & PR \\
\hline Increased & 11 & 7 & 3 \\
Decreased & 2 & 3 & 11 \\
No change & 8 & 10 & 7 \\
Total & 21 & 21 & 21 \\
$z^{\mathrm{b}}$ & -2.357 & -0.815 & 2.350 \\
$P^{\mathrm{c}}$ & 0.02 & 0.42 & 0.02 \\
\hline
\end{tabular}

almmunostaining was scored as,,,-++++++ , using the $\mathrm{H}$-scoring method. Changes in $\mathrm{H}$-score for matched pre- and post-treatment biopsies are shown.

${ }^{b}$ The Wilcoxon matched pairs signed rank test was used to determine statistically significant differences.

${ }^{\mathrm{c}} \mathrm{A}$ value of $P<0.05$ denotes a statistically significant difference. and 8 comparisons in which P-S118 levels were the same. The difference in P-S118 levels in pre- and posttreatment samples was not due to differences in total $E R \alpha$ levels, with no significant difference in the distribution of $\mathrm{ER} \alpha$ before and after treatment $(z=-$ $0.815, P=0.42$ ), whilst PR levels were significantly lower in the post-tamoxifen series, compared to the pre-treatment samples $(z=2.350, P=0.02)$.

In 11 cases, the patients relapsed whilst receiving tamoxifen. Since tamoxifen stimulates S118 phosphorylation, it is possible that the elevated P-S118 levels are due to the continued presence of tamoxifen in the blood and tissues. It has been estimated that significant levels of tamoxifen may remain in the blood for up to 6 weeks following discontinuation of administration. In the case of six of these patients, there was no difference in levels of P-S118 in the preand post-tamoxifen biopsies. For the other three cases, levels of P-S118 were increased in the resistant specimens. These data indicate that P-S118 levels do increase in a proportion of patients who have previously received tamoxifen and that the increase observed is not due solely to the presence of tamoxifen in the blood and tissues.

\section{Discussion}

We have previously used immunoblotting of extracts prepared from breast tumours to demonstrate the presence of ER $\alpha$ phosphorylated at S118 (Chen et al. 2002). In that study, S118 immunoblotting was carried out using an antibody specific for ER $\alpha$ phosphorylated at S118. Here we have employed a P-S118 antibody to develop an immunohistochemical protocol. Immunostaining of 301 breast cancer biopsies showed that a large proportion (84\%) of ER $\alpha$-positive breast tumours contain ER $\alpha$ phosphorylated at S118. As expected, statistical analysis demonstrated a positive correlation between P-S118 staining and ER $\alpha$ status. There was also a correlation between levels of P-S118 and tumour grade, with P-S118 levels being higher in lower grade tumours than in high-grade tumours. These findings indicate that phosphorylation of $\mathrm{ER} \alpha$ at $\mathrm{S} 118$ is associated with a better prognosis, perhaps indicative of functional $\mathrm{ER} \alpha$, as suggested by previous reports showing that S118 phosphorylation is induced by oestrogen binding to ER $\alpha$ (Ali et al. 1993, Joel et al. 1995, 1998, Chen et al. 2000). Despite the correlation with tumour grade, there was no significant association between S118 phosphorylation and disease-free survival or overall survival in our data. Whilst these data were being analysed, another study examining P-S118 in $113 \mathrm{ER} \alpha$-positive breast tumours reported similar 
findings, namely a negative association of P-S118 with tumour grade (Murphy et al. 2004b). Additionally, the latter study reports that phosphorylation at S118 correlates with longer disease-free survival and a trend towards better overall survival, a finding recently confirmed in another small study (Gee et al. 2005). This correlation is not held up in our considerably larger examination of $282 \mathrm{ER} \alpha$-positive primary breast cancers.

The above studies have not reported on ER $\alpha$ negative breast tumours immunostained for P-S118. Unexpectedly, in our study a small number of ER $\alpha$ negative tumours stained positive for P-S118. Previous studies have shown that breast cancer cell lines that are ER $\alpha$-negative by immunostaining and biochemically, can express ER $\alpha$ mRNA (Castles et al. 1993, 1995, Daffada et al. 1994, Poola et al. 2000). Similarly, breast tumours negative for ER $\alpha$ by IHC have been shown to express ER $\alpha$ mRNA (Shaw et al. 1996, Jarzabek et al. 2005). It is possible that ER $\alpha$ mRNA detected in ER $\alpha$-negative breast cancer cells are alternative mRNAs, such as alternative splice variants, which may generate truncated $\mathrm{ER} \alpha$ proteins some of which are not detected by IHC, such as the truncated $\mathrm{ER} \alpha$ polypeptide generated by skipping of $\mathrm{ER} \alpha$ exon 5 sequences that can be detected in the ER $\alpha$-negative BT20 cell line (Castles et al. 1993) and in breast tumours (Desai et al. 1997). Some of these variant ER $\alpha$ proteins may be phosphorylated at S118, but not detected by IHC for ER $\alpha$. It should be noted, however, that three out of the four P-S118-positive tumours had low levels of nuclear ER $\alpha$ immunostaining, with $\mathrm{H}$-scores of 10-20. Breast tumours are scored ER $\alpha$ negative for $\mathrm{H}$-scores less than 50 (McCarty et al. 1985, Goulding et al. 1995), the method also used for this study. Therefore, the P-S118 positivity in these cases may be due to high-level phosphorylation of the small amounts of ER $\alpha$ in these cells.

Although our study and the publication by Murphy et al. (2004b) indicate that S118 phosphorylation is a predictor of positive response to endocrine therapies, IHC for phosphorylated (activated) MAPK (P-MAPK) demonstrated a highly significant correlation between levels of P-S118 and P-MAPK, as has also been described for a study involving 45 breast tumours (Murphy et al. 2004a). Breast cancer cell lines that show regrowth following long-term oestrogen deprivation and show increased ER activity, demonstrate increased levels of activated ERK1/2 MAPK and some dependence on MAPK activity for proliferation in cell culture, as well as in xenografts (Jeng et al. 1998, Santen et al. 2002). P-S118 levels are also higher in these cells (Martin et al. 2003). Levels of activated
MAPK are also higher in tamoxifen-resistant MCF7 cells, as shown here. Moreover, ERK1/2 MAPK is overexpressed in some breast tumours (Sivaraman et al. 1997) and elevated MAPK activity has been correlated with lymph-node positivity (Adeyinka et al. 2002), decreased disease-free survival (Mueller et al. 2000, Gee et al. 2001) and poor response to endocrine therapy (Gee et al. 2001). In light of our finding of S118 phosphorylation being a good prognostic marker, the strong association of P-S118 with P-MAPK is surprising, since MAPK phosphorylation of S118 has been shown to result in ligand-independent activation of $E R \alpha$ (Bunone et al. 1996), which would indicate that S118 phosphorylation should correlate with reduced likelihood of response to endocrine therapies and hence poor prognosis. By contrast, although levels of P-S118 and P-MAPK were elevated in post-tamoxifen treatment biopsies compared to the pre-treatment biopsies, the change in P-S118 levels between preand post-tamoxifen biopsies was not associated with changes in P-MAPK levels in the same samples (data not shown). This indicates that other signalling pathways are involved in the increase in S118 phosphorylation, perhaps involving S118 phosphorylation by Cdk7 (Chen et al. 2000, 2002, Ito et al. 2004).

Collectively, the IHC data presented here for 301 unselected primary breast cancer biopsies show that $\mathrm{ER} \alpha$ is differentially phosphorylated at $\mathrm{S} 118$ in breast tumours. However, the data presented here do not support the contention arising from in vitro studies, which indicate that S118 phosphorylation may be predictive of failure to respond to endocrine therapies. This is confirmed by IHC performed on primary tumours from a group of patients who were initially treated with tamoxifen, relapsed and subsequently either did or did not respond to further endocrine therapy. Indeed, our findings suggest that phosphorylation of S118 is a marker of functional oestrogen signalling in breast cancer, which is amenable to inhibition by use of endocrine therapies.

We also carried out IHC for ER $\alpha$, PR, P-MAPK and P-S118 in biopsies from patients who subsequently received tamoxifen and for whom biopsies at relapse were identified. Changes in ER $\alpha$ and PR have previously been reported to be reduced at progression or relapse in patients receiving tamoxifen (Johnston et al. 1995). In the current study, PR levels were significantly lower in the post-tamoxifen treatment compared to the pre-treatment specimens, in agreement with the above report, although we did not observe a significant reduction in ER $\alpha$ expression in our series, as judged by changes in $\mathrm{H}$-score. Furthermore, it has been shown that levels of phosphorylated ERK1/2 
(P-MAPK) and phosphorylated p38 MAPK were elevated in biopsies taken from patients who relapsed whilst receiving adjuvant tamoxifen, with a small proportion of cases showing amplification and/or overexpression of HER2 (Gutierrez et al. 2005), suggesting that cross-talk between ER $\alpha$, HER2 and downstream protein kinases may contribute to tamoxifen resistance. In agreement with this idea the pre- and post-tamoxifen treatment specimens analysed here also demonstrated a significant increase in phosphorylated ERK1/2 levels.

Given these findings, the elevation in S118 phosphorylation in tamoxifen-resistant specimens was expected, especially as P-S118 levels in primary breast tumours were associated with levels of P-MAPK. However, there was no correlation between the increase in P-S118 levels and the increases in P-MAPK in the emergence of tamoxifen resistance, indicating that other signalling pathways are required for the increase in P-S118 levels, perhaps due to S118 phosphorylation by cdk7, although levels of cdk7 were not different in pre- and post-tamoxifen treatment biopsies (data not shown). However, cdk7-mediated phosphorylation of $\mathrm{S} 118$ is dependent on its recruitment to $\mathrm{ER} \alpha$ by the association of the TFIIH complex, the recruitment of TFIIH being mediated by the XPD and p62 subunits of TFIIH (Chen et al. 2000), the levels of which were not determined. Furthermore, a recent report indicates that S118 may additionally be phosphorylated by glycogen synthase kinase-3 (GSK-3) (Medunjanin et al. 2005). Altered regulation of TFIIH subunits, including the activity of cdk7 and/or GSK-3 activity could contribute to the elevated S118 phosphorylation observed here. Additionally, an interaction between ER $\alpha$ and the catalytic subunit of protein phosphatase $2 \mathrm{~A}$ or with protein phosphatase 5 results in dephosphorylation at S118 (Lu et al. 2003, Ikeda et al. 2004). Finally, results from studies in MCF7 cells indicate that ER $\propto$ turnover, localization and activity are influenced by the activities of different protein kinases, in particular MAPK (Marsaud et al. 2003). Deregulation of any of these activities may contribute to the increased levels of $\mathrm{P}-\mathrm{S} 118$ in tamoxifen-resistant cases.

We conclude that measurement of P-S118 levels is not indicative of likelihood of failure on endocrine therapies, although changes in P-S118 levels during the course of tamoxifen treatment described here raise the possibility that phosphorylation of $\mathrm{ER} \alpha$ at $\mathrm{S} 118$ is important in the emergence of resistance. Further, S118 phosphorylation in primary breast tumours is likely to be mediated by MAPK, although MAPK may not be important for S118 phosphorylation following emergence of tamoxifen resistance. Indeed, in a randomized trial using the epidermal growth factor receptor (EGFR) inhibitor Gefitinib (ZD1839, Iressa) given one month prior to surgery, P-S118 levels were reduced in 42 (79\%) of 53 tumours, with complete loss of P-S118 staining in 34\% of these tumours. There was no significant loss in total $\mathrm{ER} \alpha$ following treatment with Gefitinib (Polychronis et al. 2005). Thus, at least for EGFR-positive, ER $\alpha$-positive cases, S118 phosphorylation is likely to be mediated largely by EGFRmediated activation of MAPK.

\section{Acknowledgements}

We are grateful to members of the laboratory for helpful discussions. Particular thanks go to Dr Laki Buluwela and Dr Ross Thomas for their help with the manuscript. This work was made possible by grants from Cancer Research UK, the Breast Cancer Research Trust and the Tenovus Charity. JMG is in receipt of research grants from AstraZeneca. The authors declare that there is no conflict of interest that would prejudice the impartiality of this scientific work.

\section{References}

Adeyinka A, Nui Y, Cherlet T, Snell L, Watson PH \& Murphy LC 2002 Activated mitogen-activated protein kinase expression during human breast tumorigenesis and breast cancer progression. Clinical Cancer Research $\mathbf{8}$ 1747-1753.

Ali S \& Coombes RC 2002 Endocrine-responsive breast cancer and strategies for combating resistance. Nature Reviews in Cancer 2 101-112.

Ali S, Metzger D, Bornert JM \& Chambon P 1993 Modulation of transcriptional activation by liganddependent phosphorylation of the human oestrogen receptor A/B region. EMBO Journal 12 1153-1160.

Bunone G, Briand PA, Miksicek RJ \& Picard D 1996 Activation of the unliganded estrogen receptor by EGF involves the MAP kinase pathway and direct phosphorylation. EMBO Journal 15 2174-2183.

Buzdar A \& Howell A 2001 Advances in aromatase inhibition: clinical efficacy and tolerability in the treatment of breast cancer. Clinical Cancer Research 7 2620-2635.

Castles CG, Fuqua SA, Klotz DM \& Hill SM 1993 Expression of a constitutively active estrogen receptor variant in the estrogen receptor-negative BT-20 human breast cancer cell line. Cancer Research 53 5934-5939.

Castles CG, Klotz DM, Fuqua SA \& Hill SM 1995 Coexpression of wild-type and variant oestrogen receptor mRNAs in a panel of human breast cancer cell lines. British Journal of Cancer 71 974-980. 
Chawla A, Repa JJ, Evans RM \& Mangelsdorf DJ 2001 Nuclear receptors and lipid physiology: opening the X-files. Science 294 1866-1870.

Chen D, Riedl T, Washbrook E, Pace PE, Coombes RC, Egly JM \& Ali S 2000 Activation of estrogen receptor alpha by S118 phosphorylation involves a ligand-dependent interaction with TFIIH and participation of CDK7. Molecular Cell 6 127-137.

Chen D, Washbrook E, Sarwar N, Bates GJ, Pace PE, Thirunuvakkarasu V, Taylor J, Epstein RJ, Fuller-Pace FV, Egly JM, Coombes RC \& Ali S 2002 Phosphorylation of human estrogen receptor alpha at serine 118 by two distinct signal transduction pathways revealed by phosphorylation-specific antisera. Oncogene 21 4921-4931.

Cuzick J, Powles T, Veronesi U, Forbes J, Edwards R, Ashley S \& Boyle P 2003 Overview of the main outcomes in breast-cancer prevention trials. Lancet 361 296-300.

Daffada AA, Johnston SR, Nicholls J \& Dowsett M 1994 Detection of wild type and exon 5-deleted splice variant oestrogen receptor (ER) mRNA in ER-positive and -negative breast cancer cell lines by reverse transcription/ polymerase chain reaction. Journal of Molecular Endocrinology 13 265-273.

Desai AJ, Luqmani YA, Walters JE, Coope RC, Dagg B, Gomm JJ, Pace PE, Rees CN, Thirunavukkarasu V, Shousha S, Groome NP, Coombes R \& Ali S 1997 Presence of exon 5-deleted oestrogen receptor in human breast cancer: functional analysis and clinical significance. British Journal of Cancer 75 1173-1184.

EBCTC Group 1998 Tamoxifen for early breast cancer: an overview of the randomised trials. Lancet 351 1451-1467

Gee JM, Robertson JF, Ellis IO \& Nicholson RI 2001 Phosphorylation of ERK1/2 mitogen-activated protein kinase is associated with poor response to anti-hormonal therapy and decreased patient survival in clinical breast cancer. International Journal of Cancer 95 247-254.

Gee JM, Robertson JF, Gutteridge E, Ellis IO, Pinder SE, Rubini M \& Nicholson RI 2005 Epidermal growth factor receptor/HER2/insulin-like growth factor receptor signalling and oestrogen receptor activity in clinical breast cancer. Endocrine-Related Cancer 12 S99-S111.

Goulding H, Pinder S, Cannon P, Pearson D, Nicholson R, Snead D, Bell J, Elston CW, Robertson JF, Blamey RW et al. 1995 A new immunohistochemical antibody for the assessment of estrogen receptor status on routine formalinfixed tissue samples. Human Pathology 26 291-294.

Gutierrez MC, Detre S, Johnston S, Mohsin SK, Shou J, Allred DC, Schiff R, Osborne CK \& Dowsett M 2005 Molecular changes in tamoxifen-resistant breast cancer: relationship between estrogen receptor, HER-2, and p38 mitogenactivated protein kinase. Journal of Clinical Oncology 23 2469-2476.

Howell A, DeFriend DJ, Robertson JF, Blamey RW, Anderson L, Anderson E, Sutcliffe FA \& Walton P 1996 Pharmacokinetics, pharmacological and anti-tumour effects of the specific anti-oestrogen ICI 182780 in women with advanced breast cancer. British Journal of Cancer 74 300-308.

Howell A, Robertson JF, Abram P, Lichinitser MR, Elledge R, Bajetta E, Watanabe T, Morris C, Webster A, Dimery I \& Osborne CK 2004 Comparison of fulvestrant versus tamoxifen for the treatment of advanced breast cancer in postmenopausal women previously untreated with endocrine therapy: a multinational, double-blind, randomized trial. Journal of Clinical Oncology 22 1605-1613.

Ikeda K, Ogawa S, Tsukui T, Horie-Inoue K, Ouchi Y, Kato S, Muramatsu M \& Inoue S 2004 Protein phosphatase 5 is a negative regulator of estrogen receptor-mediated transcription. Molecular Endocrinology 18 1131-1143.

Ito S, Takeyama K, Yamamoto A, Sawatsubashi S, Shirode Y, Kouzmenko A, Tabata T \& Kato S 2004 In vivo potentiation of human oestrogen receptor alpha by Cdk7-mediated phosphorylation. Genes Cells 9 983-992.

Jarzabek K, Koda M, Kozlowski L, Mittre H, Sulkowski S, Kottler ML \& Wolczynski S 2005 Distinct mRNA, protein expression patterns and distribution of oestrogen receptors alpha and beta in human primary breast cancer: correlation with proliferation marker Ki-67 and clinicopathological factors. European Journal of Cancer 41 2924-2934.

Jeng MH, Shupnik MA, Bender TP, Westin EH, Bandyopadhyay D, Kumar R, Masamura S \& Santen RJ 1998 Estrogen receptor expression and function in long-term estrogen-deprived human breast cancer cells. Endocrinology 139 4164-4174.

Joel PB, Traish AM \& Lannigan DA 1995 Estradiol and phorbol ester cause phosphorylation of serine 118 in the human estrogen receptor. Molecular Endocrinology 9 1041-1052.

Joel PB, Traish AM \& Lannigan DA 1998 Estradiol-induced phosphorylation of serine 118 in the estrogen receptor is independent of $\mathrm{p} 42 / \mathrm{p} 44$ mitogen-activated protein kinase. Journal of Biological Chemistry 273 13317-13323.

Johnston SR \& Dowsett M 2003 Aromatase inhibitors for breast cancer: lessons from the laboratory. Nature Reviews in Cancer 3 821-831.

Johnston SR, Saccani-Jotti G, Smith IE, Salter J, Newby J, Coppen M, Ebbs SR \& Dowsett M 1995 Changes in estrogen receptor, progesterone receptor, and $\mathrm{pS} 2$ expression in tamoxifen-resistant human breast cancer. Cancer Research 55 3331-3338.

Kato S, Endoh H, Masuhiro Y, Kitamoto T, Uchiyama S, Sasaki H, Masushige S, Gotoh Y, Nishida E, Kawashima H, Metzger D \& Chambon P 1995 Activation of the estrogen receptor through phosphorylation by mitogenactivated protein kinase. Science 270 1491-1494.

Klijn JG, Blamey RW, Boccardo F, Tominaga T, Duchateau L \& Sylvester R 2001 Combined tamoxifen and luteinizing hormone-releasing hormone (LHRH) agonist versus LHRH agonist alone in premenopausal advanced breast cancer: a meta-analysis of four randomized trials. Journal of Clinical Oncology 19 343-353. 
Knowlden JM, Hutcheson IR, Jones HE, Madden T, Gee JM, Harper ME, Barrow D, Wakeling AE \& Nicholson RI 2003 Elevated levels of epidermal growth factor receptor/c-erbB2 heterodimers mediate an autocrine growth regulatory pathway in tamoxifen-resistant MCF-7 cells. Endocrinology 144 1032-1044.

Le Goff P, Montano MM, Schodin DJ \& Katzenellenbogen BS 1994 Phosphorylation of the human estrogen receptor, Identification of hormone-regulated sites and examination of their influence on transcriptional activity. Journal of Biological Chemistry 269 4458-4566.

Lu Q, Surks HK, Ebling H, Baur WE, Brown D, Pallas DC \& Karas RH 2003 Regulation of estrogen receptor alphamediated transcription by a direct interaction with protein phosphatase 2A. Journal of Biological Chemistry 278 4639-4645.

Lykkesfeldt AE, Madsen MW \& Briand P 1994 Altered expression of estrogen-regulated genes in a tamoxifenresistant and ICI 164,384 and ICI 182,780 sensitive human breast cancer cell line, MCF-7/TAMR-1. Cancer Research 54 1587-1595.

McCarty KS, Jr, Miller LS, Cox EB, Konrath J \& McCarty KS, Sr 1985 Estrogen receptor analyses. Correlation of biochemical and immunohistochemical methods using monoclonal antireceptor antibodies. Archives of Pathology and Laboratory Medicine 109 716-721.

Madsen MW, Reiter BE, Larsen SS, Briand P \& Lykkesfeldt AE 1997 Estrogen receptor messenger RNA splice variants are not involved in antiestrogen resistance in sublines of MCF-7 human breast cancer cells. Cancer Research 57 585-589.

Marsaud V, Gougelet A, Maillard S \& Renoir JM 2003 Various phosphorylation pathways, depending on agonist and antagonist binding to endogenous estrogen receptor alpha (ERalpha), differentially affect ERalpha extractability, proteasome-mediated stability, and transcriptional activity in human breast cancer cells. Molecular Endocrinology 17 2013-2027.

Martin LA, Farmer I, Johnston SR, Ali S, Marshall C \& Dowsett M 2003 Enhanced estrogen receptor (ER) alpha, ERBB2, and MAPK signal transduction pathways operate during the adaptation of MCF-7 cells to long term estrogen deprivation. Journal of Biological Chemistry 278 30458-30468.

Medunjanin S, Hermani A, De Servi B, Grisouard J, Rincke G \& Mayer D 2005 Glycogen synthase kinase-3 interacts with and phosphorylates estrogen receptor alpha and is involved in the regulation of receptor activity. Journal of Biological Chemistry 280 33006-33014.

Mueller H, Flury N, Eppenberger-Castori S, Kueng W, David F \& Eppenberger U 2000 Potential prognostic value of mitogen-activated protein kinase activity for disease-free survival of primary breast cancer patients. International Journal of Cancer 89 384-388.
Murphy L, Cherlet T, Adeyinka A, Niu Y, Snell L \& Watson P 2004a Phospho-serine-118 estrogen receptor-alpha detection in human breast tumors in vivo. Clinical Cancer Research 10 1354-1359.

Murphy LC, Niu Y, Snell L \& Watson P 2004b Phosphoserine-118 estrogen receptor-alpha expression is associated with better disease outcome in women treated with tamoxifen. Clinical Cancer Research 10 5902-5906.

Osborne CK 1998 Tamoxifen in the treatment of breast cancer. New England Journal of Medicine 339 1609-1618.

Polychronis A, Sinnett HD, Hadjiminas D, Singhal H, Mansi JL, Shivapatham D, Shousha S, Jiang J, Peston D, Barrett N et al. 2005 Preoperative gefitinib versus gefitinib and anastrozole in postmenopausal patients with oestrogen-receptor positive and epidermal-growthfactor-receptor-positive primary breast cancer: a double-blind placebo-controlled phase II randomised trial. Lancet Oncology 6 383-391.

Poola I, Koduri S, Chatra S \& Clarke R 2000 Identification of twenty alternatively spliced estrogen receptor alpha mRNAs in breast cancer cell lines and tumors using splice targeted primer approach. Journal of Steroid Biochemistry and Molecular Biology 72 249-258.

Powles TJ 2002 Anti-oestrogenic prevention of breast cancer-the make or break point. Nature Reviews in Cancer 2 787-794.

Ring A \& Dowsett M 2004 Mechanisms of tamoxifen resistance. Endocrine Related Cancer 11 643-658.

Robertson JF 1996 Oestrogen receptor: a stable phenotype in breast cancer. British Journal of Cancer 73 5-12.

Santen RJ, Song RX, McPherson R, Kumar R, Adam L, Jeng MH \& Yue W 2002 The role of mitogen-activated protein (MAP) kinase in breast cancer. Journal of Steroid Biochemistry and Molecular Biology 80 239-256.

Shaw JA, Walsh T, Chappell SA, Carey N, Johnson K \& Walker RA 1996 Microsatellite instability in early sporadic breast cancer. British Journal of Cancer 73 1393-1397.

Sivaraman VS, Wang H, Nuovo GJ \& Malbon CC 1997 Hyperexpression of mitogen-activated protein kinase in human breast cancer. Journal of Clinical Investigation 99 1478-1483.

Taylor CW, Green S, Dalton WS, Martino S, Rector D, Ingle JN, Robert NJ, Budd GT, Paradelo JC, Natale RB et al. 1998 Multicenter randomized clinical trial of goserelin versus surgical ovariectomy in premenopausal patients with receptor-positive metastatic breast cancer: an intergroup study. Journal of Clinical Oncology 16 994-999.

Therasse P, Arbuck SG, Eisenhauer EA, Wanders J, Kaplan RS, Rubinstein L, Verweij J, Van Glabbeke M, van Oosterom AT, Christian MC \& Gwyther SG 2000 New guidelines to evaluate the response to treatment in solid tumors, European Organization for Research and Treatment of Cancer, National Cancer Institute of the United States, National Cancer Institute of Canada. Journal of the National Cancer Institute 92 205-216. 